\title{
STUDY ON MECHANICAL PROPERTIES OF CONCRETE-FILLED STEEL TUBULAR SHORT COLUMNS UNDER DIFFERENT CURING TEMPERATURES
}

\section{KWEKU DARKO FORSON \& MA QINYONG}

School of Civil Engineering and Architecture, Anhui University of Science and Technology,

Huainan 232001, Anhui, China

\begin{abstract}
In order to study the bearing capacity of cylindrical concrete-filled steel tube (CFST) short column under axial compression, curing age and curing temperature were taken as variables, The uniaxial compressive tests of CFST short columns were carried out, the stress-time multiplied curves and the total energy of the tests were obtained and the compressive strength of CFST at different curing temperatures in different stages at low temperature was compared. The results show that the strength of concrete-filled steel tube increases with the decrease of curing temperature and the total energy in the compression process also shows the same rule. Finally, the mechanism of strength participation of each phase at low temperature is analyzed, and the influencing factors of strength of concrete-filled steel tube at low temperature are expounded. Based on the principle of energy analysis, the deformation process of concrete-filled steel tube specimen is studied, which provides the research basis and way for the deformation analysis of this kind of material under low temperature condition.
\end{abstract}

KEYWORDS: Uniaxial compression test, concrete-filled steel tube, Low temperature curing, total absorbed energy

Received: Mar 10, 2021; Accepted: Mar 30, 2021; Published: Apr 09, 2021; Paper Id.: IJCSEIERDJUN20213

\section{INTRODUCTION}

Concrete-filled steel tube (CFST) is a new type of structure evolved and developed on the basis of reinforced concrete and spiral reinforced concrete (Mander et al., 1988). It uses the mutual restriction of steel tube and concrete in the stress process to make it have excellent performance (Gardner et al., 1967). This is because, on the one hand, the restraint effect of steel tube on concrete makes the concrete not only improve its strength, but also enhance its plasticity and ductility under three-dimensional stress; on the other hand, the existence of concrete improves the stability of steel tube (Han et al., 2000). Through the combination of the two materials, the concretefilled steel tube has the advantages of high bearing capacity, good toughness and plasticity, superior seismic and fire resistance performance, saving materials and convenient construction (Han et al., 2002). However, it is also because of the interaction between the two materials that the mechanical properties of concrete-filled steel tubular (CFST) are complex. Concrete-filled steel tubular structure can better adapt to the development of modern engineering structure to long-span, high-rise, heavy load and bear the needs of harsh conditions in line with the industrialization requirements of modern construction technology, because it is more and more widely used in industrial plants, arch bridges and high-rise buildings (Konno, K. et al., 1998).

When the composite structure is subjected to axial pressure, due to the different transverse deformation coefficients of the steel tube and the core concrete, the interaction hoop force is generated between them (Lam et al., 2004). The hoop force makes the core concrete three-way compression, delays the expansion of its internal micro 
cracks, and greatly improves the compressive strength; at the same time, the existence of the core concrete also effectively ensures the local stability of the thin-walled steel tube (Nishiyama, I et al., 2004); the two make up for each other's weaknesses, and give full play to the advantages of the two materials, which is also the advantage of the concrete-filled steel tube composite structure. In addition to the advantages of high compressive strength, concrete-filled steel tube also has good plasticity and toughness, simple construction, no formwork, shortened construction period, greatly saving steel, wood and cement, and remarkable economic benefits (Chen, S et al., 2018).

In the bridge and tunnel projects in the central and western regions of China, the importance of projects in extremely cold frozen regions is becoming increasingly apparent (Bradford et al., 2002). For concrete-filled steel tubular structures, first of all, we must have a full understanding of the mechanical properties of the materials that make up the structure, so that we can have a better grasp of the performance of the whole structure (O'Shea et al., 1998). Concrete-filled steel tube structure is composed of steel tube and concrete (Yu, Q et al., 2008). First of all, due to the constraint of steel tube on concrete, the core concrete is in a complex stress state, and its low-temperature properties have a qualitative change, from the original brittle failure to ductile plastic failure, so that the ductility of the whole structure is improved (Uy, B et al., 1998). Secondly, due to the existence of concrete, the steel tube is also in a complex stress state. At the same time, the existence of concrete inhibits the premature occurrence of local buckling of steel tube (ACI Committee et al., 2005).

It can be seen that through the combination of the two materials, the concrete-filled steel tubular members give full play to the advantages of the two materials, so that the bearing capacity can be improved and the ductility can be improved (Kitada, T et al., 1998). However, when CFST structure is used in low temperature area, there is a lack of quantitative analysis on the influence of material curing period and temperature on the technical indexes of CFST (Fukumoto, Y et al., 1997). Concrete-filled steel tubular structure is convenient for prefabrication and construction, and it also has good mechanical properties at very low temperature, so it is very suitable for the construction of buildings in low temperature environment. This paper discusses the mechanical properties of steel pipe prefabricated parts of concrete with given strength grade in low temperature environment, which has practical significance for the quality evaluation of construction site in perennial low temperature area (Wakabayashi, M et al., 1994).

\section{MATERIAL AND METHODS}

Q235 seamless steel pipe with the height of $320 \mathrm{~mm}$, the outer diameter of $16 \mathrm{~mm}$ and the thickness of $4 \mathrm{~mm}$ was used in the experiment. C30 concrete was designed according to the code for design of mix proportion of ordinary concrete (JGJ55-2011). The size of the test was $\Phi 160 \mathrm{~mm} \times \mathrm{H} 320 \mathrm{~mm}$. The bottom is welded with a closed steel plate base, which is completely vertical to the steel pipe with a thickness of $5 \mathrm{~mm}$.

The curing time was 3 days, 7 days and 28 days, and the curing temperature was set at $20^{\circ} \mathrm{C},-10^{\circ} \mathrm{C}$ and $-20^{\circ} \mathrm{C}$. According to the above variables, a total of 54 concrete-filled steel tubular short columns were made by orthogonal test. Three groups of test blocks were cured for $3 \mathrm{~d}, 7 \mathrm{~d}$ and $28 \mathrm{~d}$ respectively; the other two groups were cured for $3 \mathrm{~d}, 7 \mathrm{~d}$ and $28 \mathrm{~d}$ respectively at $-10^{\circ} \mathrm{C}$ and $-20^{\circ} \mathrm{C}$. The mechanical properties of concrete at low temperature depend on many factors, such as temperature, strength grade, moisture content, cooling and loading rate. This paper only considers the influence of different low temperature on the compressive strength of concrete-filled steel tubular specimens. 
After reaching the specified age, each group of test blocks were taken out for uniaxial compressive strength test at room temperature. The uniaxial compressive strength test is carried out according to the standard for test methods of physical and mechanical properties of concrete (GB/T 50081-2019). The loading rate is 5mm/min, and the measurement starts when the loading reaches $100 \mathrm{kN}$. The loading rate is changed to $0.5 \mathrm{~mm} / \mathrm{min}$. The loading diagram is shown in Figure 1. There are three parallel concrete samples in each group and the average value is taken.

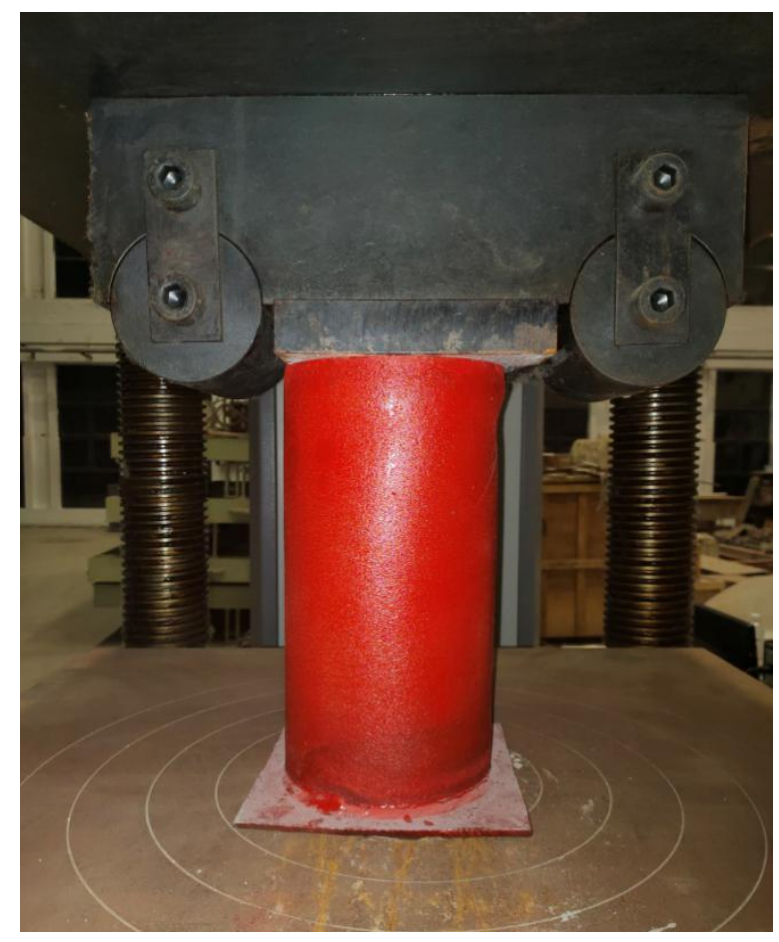

Figure 1: Schematic Diagram of Compression Test

\section{TESTRESULTSANDANALYSIS}

\section{Analysis of Stress-strain Curves}

Concrete-filled steel tubular usually exists in the form of short column with axial pressure in actual structure. The classic curve of compression of concrete-filled steel tubular short column is shown in Figure 2. The working process of concretefilled steel tubular specimen is mainly: in the initial stage of applying external load because the Poisson ratio of steel tube is larger than that of concrete, the initial transverse deformation of concrete is not large when the external load is applied and the outer steel pipe has no restriction on it. The stress transfer between them is mainly carried out by bonding between the inner wall of steel tube and the inner wall of concrete, which basically works separately; with the increase of external load, when the lateral deformation of core concrete reaches a certain value, its Poisson ratio also reaches or approaches the Poisson ratio of steel pipe and the steel pipe wall will be subjected to the radial compressive stress of the core concrete and the steel pipe will also mix with the core. The concrete has radial compressive stress. At this time, the outer steel pipe starts to exert "restraint effect" on the core concrete, while the core concrete also supports the steel pipe, which can prevent the buckling of the pipe wall. At this time, it shows the advantages of concrete-filled steel tube; when the external load reaches the limit state of concrete-filled steel tube, the steel tube wall buckles, and the core concrete is crushed, and the member is destroyed. 


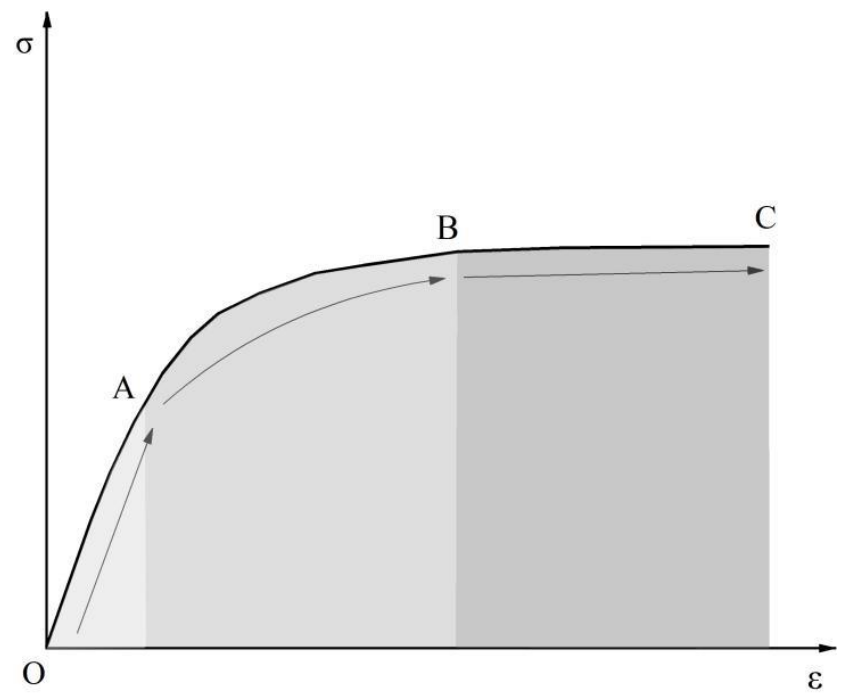

Figure 2: Stress-strain Curves of Concrete-filled Steel Tube

The performance analysis of each stage of the whole curve is as follows.

\section{(1) Elastic stage (O-A)}

At this stage, the steel tube and core concrete are generally stressed separately, and point A is roughly equivalent to the starting point of the steel into the elastic-plastic stage. The original cracks, pores and microcracks in the concrete sample close gradually. In this stage, the press continuously inputs energy to the concrete, and the energy increases slowly with the increase of strain. Part of the energy absorbed by the concrete sample is converted into the releasable elastic potential energy, and the other part is dissipated by the primary cracks and pore closure of the concrete. At the same time, the steel tube is basically in the elastic stage, and the deformation is small.

\section{(2) Elastoplastic stage (A-B)}

After entering this stage, under the action of longitudinal pressure, the micro cracks of the core concrete continue to expand, so that the transverse deformation coefficient exceeds the Poisson's ratio of the steel tube, resulting in the hoop force. The core concrete is restrained by steel tube, and its performance is completely different from that of plain concrete. With the increase of longitudinal deformation, the hoop force increases. At point B, the steel generally enters the elasticplastic stage.

\section{(3) Plastic strengthening section (B-C)}

When the steel pipe enters the plastic stage, it will bear higher stress and yield gradually. A large number of new microcracks are generated, propagated and converged in the steel pipe, and obvious plastic deformation occurs. The hoop force continues to increase, and the curve amplitude continues to increase. The curve strengthening stage can continue to increase; it is limited to the range of the machine, so the experiment is stopped after loading to 2500 s.

\section{Analysis of Compressive Strength Different Curing Age}

The stress time multiplication curve of concrete-filled steel tubular stub columns under different curing temperatures is shown in Figure 3. 


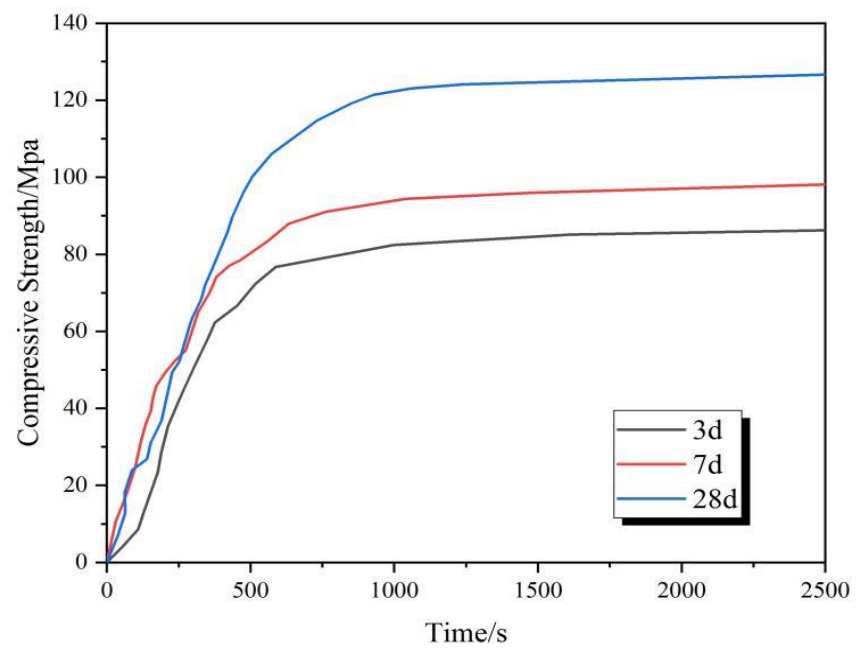

(a) $20^{\circ} \mathrm{C}$

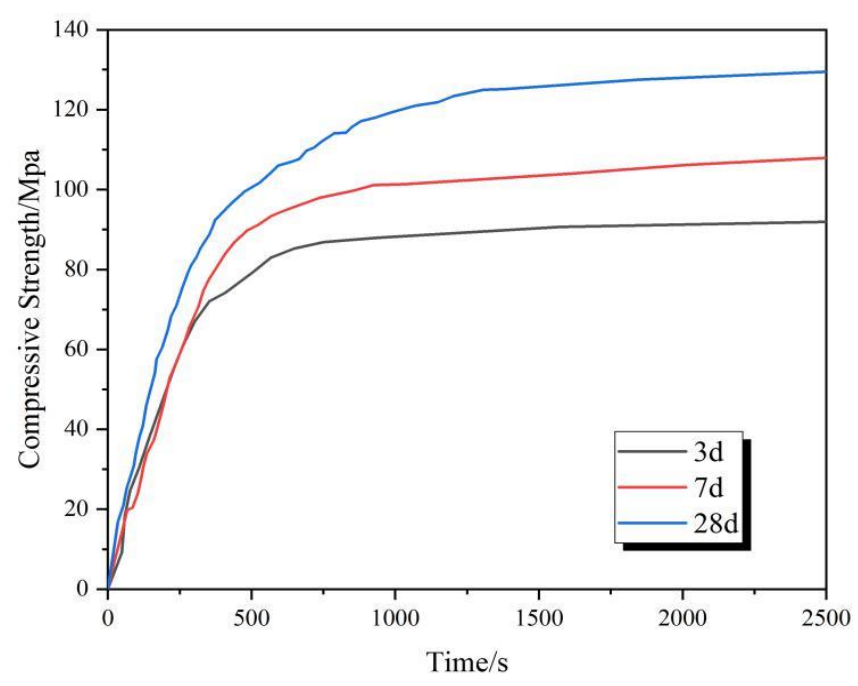

(b) $-10^{\circ} \mathrm{C}$

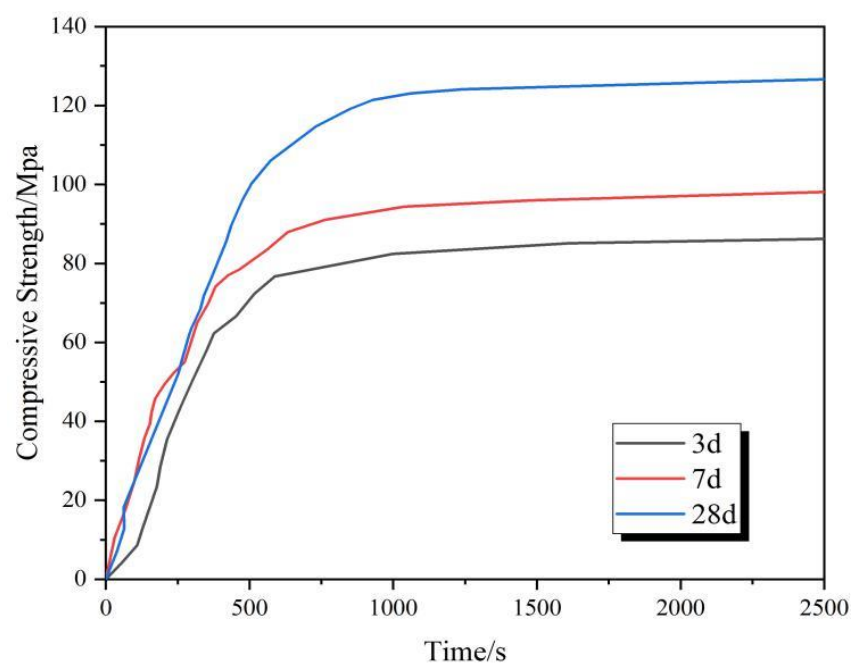

(c) $-20^{\circ} \mathrm{C}$

Figure 3: Stress Time Multiplication Curve of Concrete-filled Steel Tubular Short Columns Under Axial Compression 
It can be seen from figure 3 that the concrete strength increases with time under different curing ages. When the local buckling of the steel tube wall occurs, the bearing capacity of the concrete-filled steel tube members will be affected. This effect is mainly reflected in two aspects: on the one hand, it makes the steel tube section of the buckling part withdraw from the work ahead of time; on the other hand, it reduces the restraint effect of the steel tube on the concrete. In short, the bearing capacity of thin-walled concrete-filled steel tubular members will decrease with the occurrence of local buckling. The bearing capacity of thin-walled concrete-filled steel tubular (CFST) members decreases significantly due to the early withdrawal of some sections of the steel tube. In addition, when the local buckling of concrete-filled steel tube occurs, the contact surface between the steel tube wall and the concrete at the local buckling position will be separated and the macroscopic appearance is that the steel tube wall appears local protrusion.

With the increase of concrete-filled steel tube curing age, the strength of the specimen also increases and the change of temperature has no obvious effect on this rule. This is because in this temperature range, the concrete can still carry out normal hydration reaction, so as to obtain the improvement of mechanical properties.

\section{Analysis of Compressive Strength Different Curing Temperatures}

The stress time multiplication curve of concrete-filled steel tubular short columns under axial compression under different curing ages is shown in figure 4. It can be seen from the stress time multiplication curve of specimens at the same age in different curing temperatures that with the decrease of temperature, the strength of concrete-filled steel tube test block increases gradually. This is because with the decrease of temperature, the pore solution in concrete freezes continuously, and the pores will be filled by ice with higher strength, and the solutes contained in some pore solutions can also improve the ice strength. In addition, the adhesion strength between ice and silicate material with hydrophilic matrix will increase with the decrease of temperature, which will make the strength of concrete increase continuously.

The growth rate of compressive strength of concrete specimen shows a trend of first fast and then slow, which is mainly due to two aspects: the freezing point of solution in the hole is related to the size of corresponding hole and decreases with the decrease of hole size. The growth rate of compressive strength changes most obviously at the age of 7 days, which indicates that the filling effect of ice in the micropores of the specimens at this age is the most effective on the compressive strength; when all the pore solutions are frozen, the pores that are not filled with ice will continue to shrink with the decrease of temperature, and the concrete density is higher, but it is not as obvious as the growth caused by ice filling. The compressive failure load is mainly in the axial direction, which is only related to the filling of ice to the pores. Due to the same moisture content, the difference of compressive strength of $28 \mathrm{~d}$ CFST is not obvious, but it is still dominated by temperature variable. 


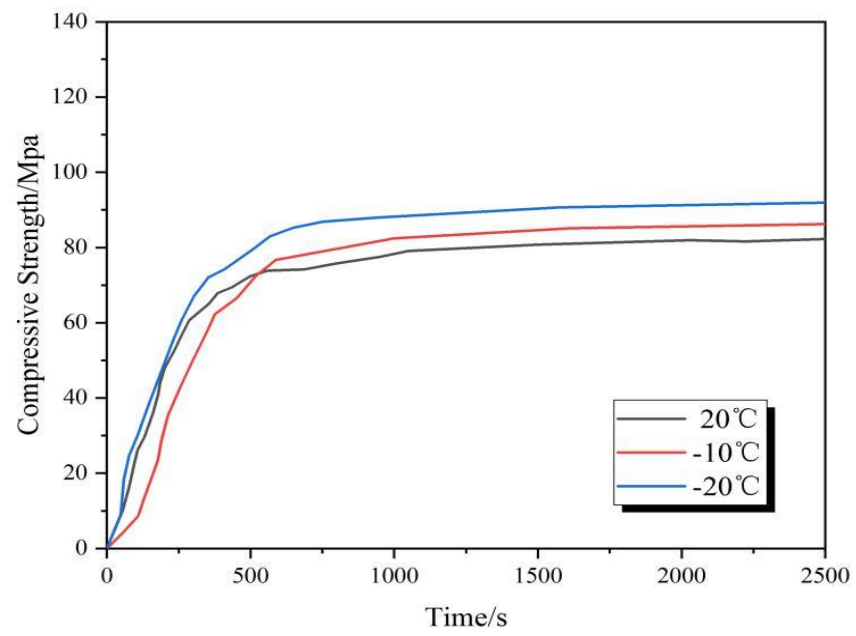

(a) $3 \mathbf{d}$

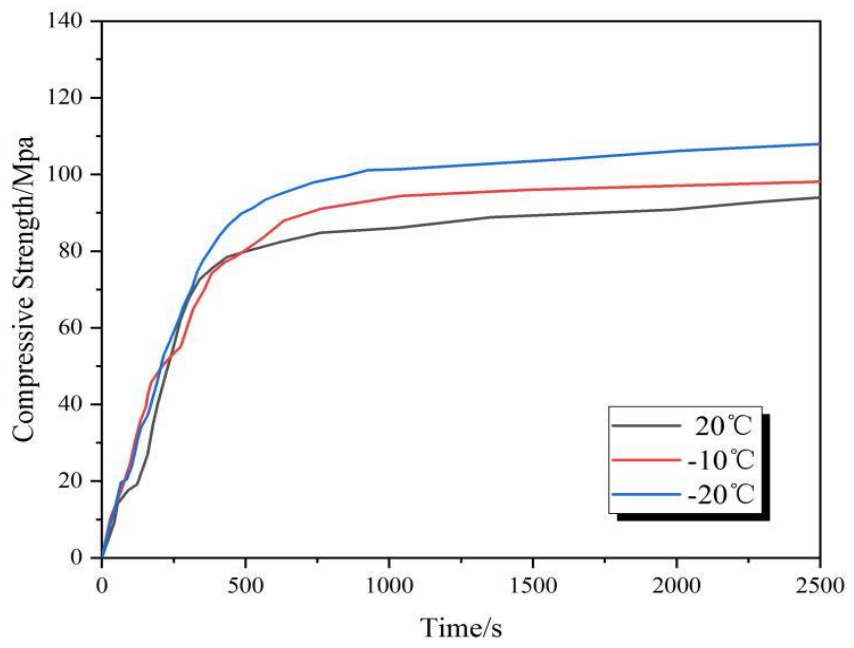

(b) $7 \mathbf{d}$

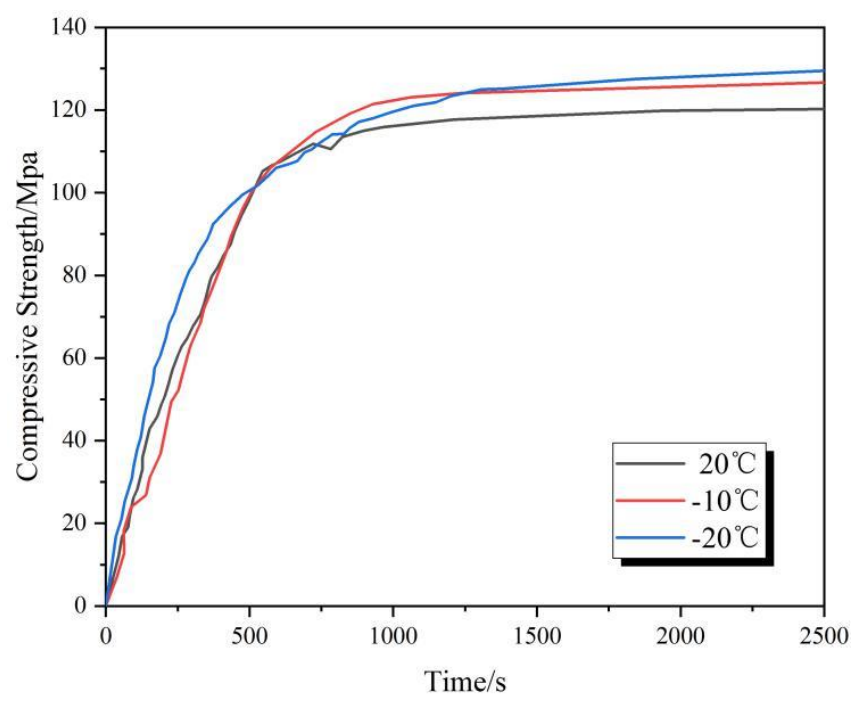

(c) $28 d$

Figure 4: Stress Time Multiplication Curve of Concrete-filled Steel Tubular Short Columns Under Axial Compression 


\section{TOTAL ENERGY ANALYSISOF UNIAXIAL COMPRESSION TEST}

In the process of uniaxial compression of low-temperature concrete with the accumulation and dissipation of energy, the deformation and failure of low-temperature concrete are driven by energy. In order to study the mechanical properties and energy evolution of low temperature concrete under uniaxial compression, uniaxial compression tests were carried out. From the point of view of the evolution law of the total energy, the total energy and the total energy of the concrete in the low-temperature curing period, the influence of the low temperature curing time on the total energy are analyzed.

Assuming that there is no heat exchange between the compression failure of the concrete sample and the outside world, the total energy $\mathrm{Q}$ input by the press to the concrete sample is absorbed completely. In this experiment, because the deformation is determined, that is, the loading time and loading rate are fixed and there is no peak stress in the specimen, the energy consumption ratio of the specimen under the same deformation can be analyzed, so as to analyze the curing temperature and the influence of age on the total energy of the specimen.

According to the calculation formula below:

$$
Q=\int_{0}^{\varepsilon_{0}} \sigma_{0} d \varepsilon_{0}
$$

The total energy of the specimen is the coordinate area of the stress-strain curve, as shown in the figure below. After the area is summed up, it can be obtained from table 1 that the highest total energy value can be obtained for the concrete-filled steel tubular specimen in the $28 \mathrm{~d}-20^{\circ} \mathrm{C}$ curing environment, and the lowest total energy value can be obtained in the $3 \mathrm{~d} 20^{\circ} \mathrm{C}$ curing environment. The results are shown in Figure 5.
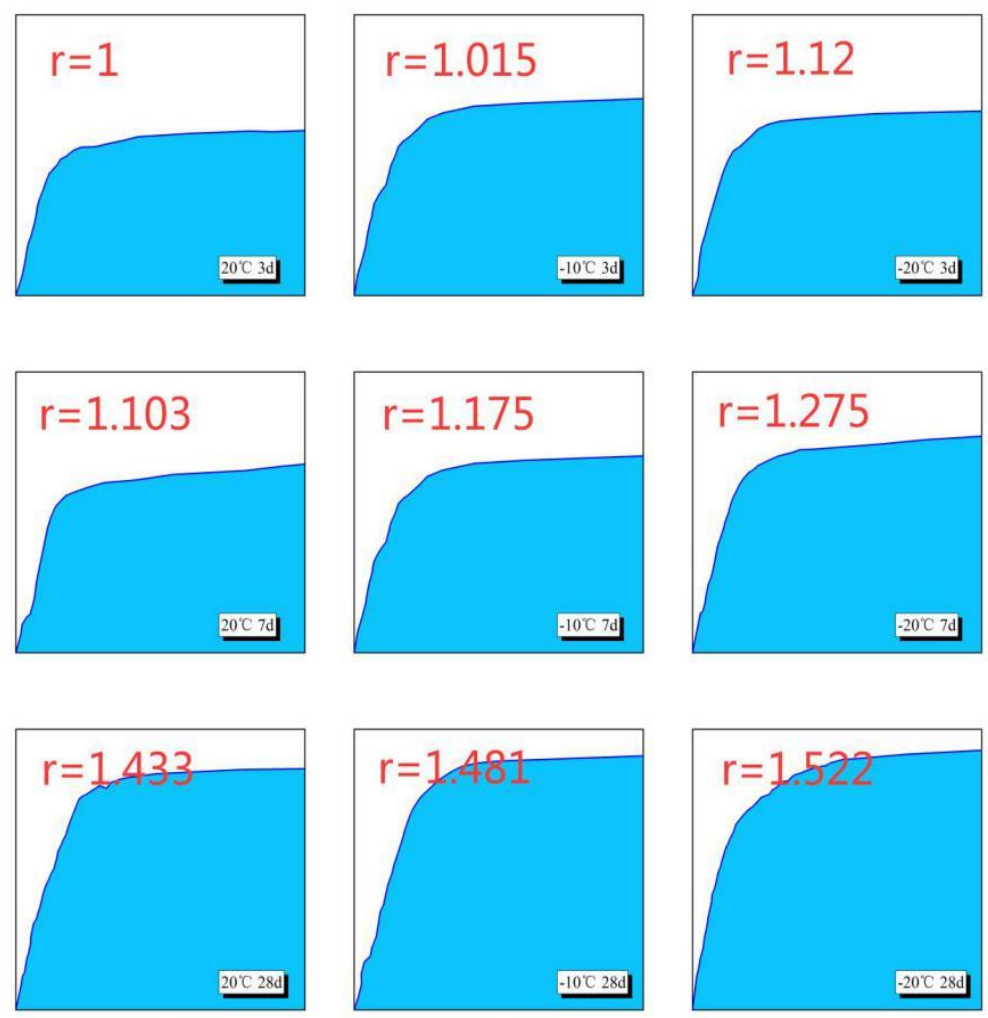

Figure 5: Energy Values of All CFST Groups. 


\section{Effects of Age on Energy Evolution}

As shown in Figure 6, in different temperature curing environment, the total energy of concrete in the compression test process of each age presents an exponential growth trend. This law has the same performance at all temperatures because the reaction process of concrete hydration strength is not affected by the temperature too much. In the low temperature environment, the total energy of concrete-filled steel tubular specimens can still reach the design expected value.

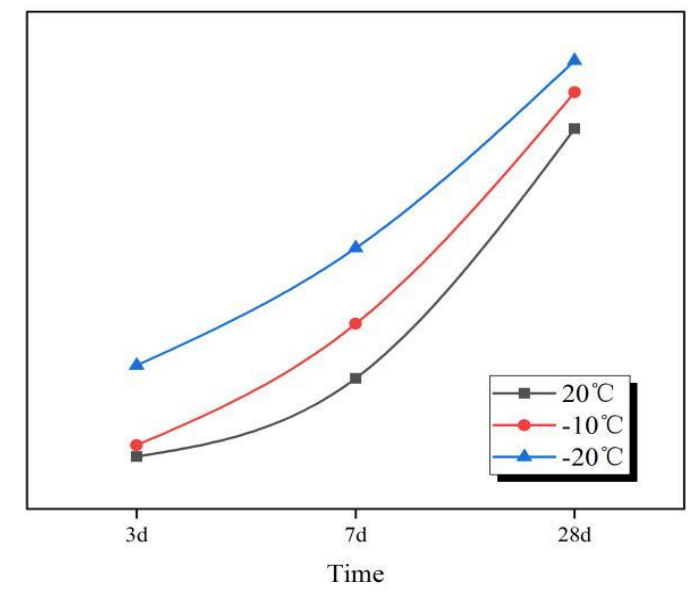

Figure 6: The Change Curve of Each Energy with Curing Age

The strength of concrete-filled steel tubular specimens cured at $20^{\circ} \mathrm{C}$ is significantly lower than $-20^{\circ} \mathrm{C}$ at all ages The reason is that the dominant effect of temperature on the strength of concrete is mainly reflected in the filling and reinforcement of pore water solution condensed into ice, and the influence on the hydration process of concrete itself is not obvious.

\section{Effects of Temperature on Energy Evolution}

As shown in Figure 7, under different curing temperatures, the total energy under the same strain of concrete-filled steel tube specimens at the same age gradually increases with the decrease of temperature. This is because with the gradual decrease of curing temperature, the pore water solution in the concrete specimens transforms into ice crystals and the tiny ice crystals in the concrete specimens at the compaction stage absorb a lot of energy and contribute extra strength.

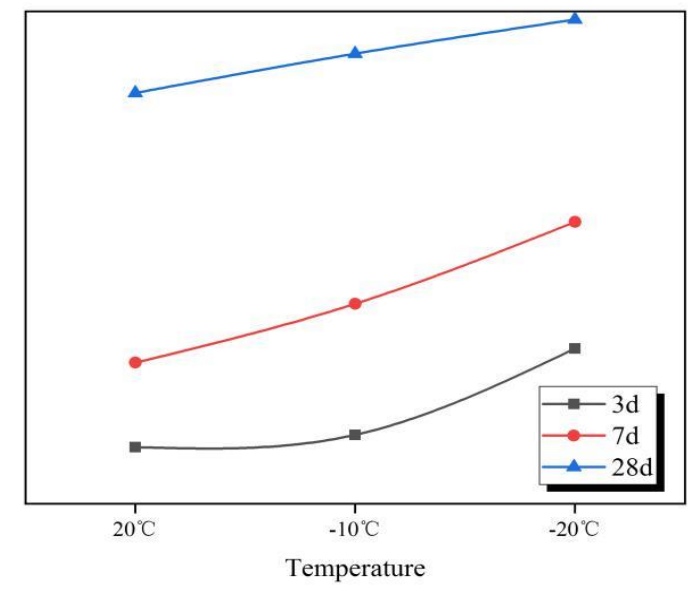

Figure 7: Relation Curve between Energy and Curing Temperature 
At the same time, it can be seen in the figure that the total energy of the specimen is very sensitive to the change of curing temperature when the specimen is in $3 \mathrm{~d}$. With the gradual increase of curing age, the sensitivity to temperature also decreases. This is because in the process of curing, the unhydrated water content in the pores of concrete specimens decrease continuously, which makes the ice crystal content decrease at low temperature, thus the contribution to energy absorption is low.

\section{CONCLUSIONS}

- Due to the restraint effect of steel tube on concrete core, the hoop force of steel tube on core concrete makes the strength of concrete specimen significantly improved compared with plain concrete column.

- The low temperature environment has no obvious effect on the axial compressive strength of concrete-filled steel tubular and it increases significantly with the increase of curing age of concrete-filled steel tubular specimens.

- Compared with $20^{\circ} \mathrm{C}$ curing, the axial compressive strength of concrete samples at $-20^{\circ} \mathrm{C}$ and $-10^{\circ} \mathrm{C}$ is improved in varying degrees and the increase is most obvious at 7 days. The reduction of curing temperature can significantly improve the ability of specimens to resist failure.

- It can be seen from the comparison of the total energy during the compression process that the total energy of the specimens increases exponentially with the increase of the curing age of the concrete-filled steel tube specimens, and the specimens cured at low temperature also provide additional energy absorption area because of the existence of ice crystals and the total energy increases with the decrease of temperature.

- In the young age, the sensitivity of total energy of CFST compression specimens to temperature is higher than that in the old age. This is because the water content of the specimens in the young age is the largest and the ice crystals in the pores are also the largest. The lower the temperature is, the fuller the filling effect of ice crystals is.

\section{REFERENCES}

1. Mander, J. B., Priestley, M. J. N., \& Park, R. (1988). Observed stress-strain behavior of confined concrete. Journal of structural engineering, 114(8), 1827-1849.

2. Gardner, N. J., \& Jacobson, E. R. (1967, July). Structural behavior of concrete-filled steel tubes. In Journal Proceedings (Vol. 64, No. 7, pp. 404-413).

3. Golshahr, Alireza, et al. "Multi wall carbon nanotube reinforced silicone for aerospace applications." Int. J. Mech. Prod. Eng. Res. Dev 8.4 (2018): 743-752.

4. Han, L. H. (2000). Tests on concrete-filled steel tubular columns with high slenderness ratio. Advances in Structural Engineering, 3(4), 337-344.

5. Han, L. H. (2002). Tests on stub columns of concrete-filled RHS sections. Journal of Constructional Steel Research, 58(3), 353-372.

6. Konno, K., Sato, Y., Kakuta, Y., \& Ohira, M. (1998). The property of recycled concrete column encased by steel tube subjected to axial compression. Transactions of the Japan Concrete Institute, 19, 231-238.

7. Lam, D., \& Williams, C. A. (2004). Experimental study on concrete-filled square hollow sections. Steel and Composite Structures, 4(2), 95-112. 
8. Ramaswamy, R., et al. "Investigation of densification behaviour on yttrium oxide reinforced Ti-6Al-4V nano-composite through powder metallurgy." Int J Mech Prod Eng Res Dev 8.2 (2018): 433-442.

9. British Standards Institution. (1994). Eurocode 4--design of Composite Steel and Concrete Structures: Eurocode 4: Conception Et Dimensionnement Des Structures Mixtes Acier-beton--Partie 1.1: Regles Generales Et Regles Pour Les Batiments (y Compris Le Document D'application Nationale Pour Le Royaume Uni). General Rules and Rules for Buildings (together with United Kindom National Application Document). BSI.

10. Mehdi, Hayder A., and MARYAM SINAN RASHEED. "Effect of Slenderness Ratio on the Behavior of Reinforced Concrete Column Confined with Carbon Fiber Reinforced Polymer Composites Under Axial Load." International Journal of Civil, Structural, Environmental and Infrastructure Engineering Research and Development (IJCSEIERD) 7.6 (2017): 1-20.

11. Nishiyama, I. (2002). Summary of research on concrete-filled structural steel tube column system carried out under the USJapan cooperative research program on composite and hybrid structures. Building Research Inst..

12. Chen, S., Zhang, R., Jia, L. J., Wang, J. Y., \& Gu, P. (2018). Structural behavior of UHPC filled steel tube columns under axial loading. Thin-Walled Structures, 130, 550-563.

13. Bradford, M. A., Loh, H. Y., \& Uy, B. (2002). Slenderness limits for filled circular steel tubes. Journal of Constructional Steel Research, 58(2), 243-252.

14. Siva, R., et al. "Experimental investigation of stitched and unstitched bamboo fiber using sugarcane powder." International Journal of Mechanical and Production Engineering Research and Development 8.2 (2018): 1095-1104.

15. O'Shea, M. D., \& Bridge, R. Q. (1998). Tests on circular thin-walled steel tubes filled with medium and high strength concrete. Australian civil engineering transactions, 40, 15.

16. Yu, Q., Tao, Z., \& Wu, Y. X. (2008). Experimental behaviour of high performance concrete-filled steel tubular columns. ThinWalled Structures, 46(4), 362-370.

17. Uy, B. (1998). Concrete-filled fabricated steel box columns for multistorey buildings: behaviour and design. Progress in Structural Engineering and Materials, 1(2), 150-158.

18. Irfan, Osama Mohamed. "INFLUENCE OF SPECIMEN GEOMETRY AND LUBRICATION CONDITIONS ON THE COMPRESSIONBEHAVIOR OF AA6066 ALUMINUM ALLOY." International Journal of Mechanical Engineering (IJME) 5.1: 14-24.

19. ACI Committee. (2005). Building code requirements for structural concrete (ACI 318-05) and commentary (ACI 318R-05). American Concrete Institute.

20. Design, A. S. (1999). Specification for structural steel buildings. AISC, December, 27.

21. Kitada, T. (1998). Ultimate strength and ductility of state-of-the-art concrete-filled steel bridge piers in Japan. Engineering structures, 20(4-6), 347-354.

22. Jacob, Anoop, and Nivin Philip. "A review on high performance concrete." International Journal of Civil Engineering (IJCE) 4.6 (2015): 39-46.

23. Fukumoto, Y. (1997). Structural stability design. Steel and composite structures, 1-7.

24. Wakabayashi, M. (1994). Recent development and research on composite and mixed building in japan. In Proc. of the 4th ASCCS International Conference (Vol. 237, p. 242). Bratislava, Slobakia. 
